\title{
Acute lithium toxicity: Two cases with different outcomes
}

Sir,

Lithium toxicity is known for its diverse clinical manifestations ranging from mild tremor to severe coma and death. We report two cases of lithium toxicity.

A 25-year-old lady taking treatment for bipolar disorder in form of tab lithium (800 mg/day) and carbamazepine (400 mg/day) for the last six months. She was admitted with tremor for 15 days, altered sensorium for three days and generalized tonic clonic seizure for one day.

On admission her Glasgow coma scale (GCS) score was E2 M1 V1, pulse was 90\min and BP was $100 \backslash 70 \mathrm{~mm} \mathrm{Hg}$. She was dehydrated. Nystagmus was present in both eyes. She had coarse tremors present all over body with generalized rigidity. Investigations [Table 1] revealed leucocytosis, high serum lithium level (4.86 meq/l) and high serum creatinine and urea.

She was given five cycles of hemodialysis session, each lasting for $4 \mathrm{hrs}$ daily. Patient was also given injection phenytoin for control of seizure and antibiotics. On Day 3 she was alert and her GCS was E4 M4V5 but she had bilateral carpopedal spasm. She was given injection calcium gluconate as her serum calcium was markedly low. On Day 7 her GCS was 15. She was able to stand with little support and was ataxic, had dysarthria and had cerebellar signs in both upper limbs. On Day 15 she was discharged with mild gait ataxia which persisted for approximately three months.

Our second case was a 48-year-old gentleman taking lithium $600 \mathrm{mg} /$ day and sodium valproate $1 \mathrm{~g} /$ day for manic depressive psychosis for four years presented with diarrhea and vomiting for 15 days, tremor for 10 days, generalized tonic clonic seizure for seven days, altered sensorium for five days. His pulse rate was 110/min and had hypotension(80/50 mm Hg). His GCS was E2M1V1. All deep tendon reflexes were brisk with bilateral extensor plantar. Investigations revealed [Table 1] high serum (2.8 meq/l) lithium level and hypothyroidism. Chest X-ray was suggestive of right-sided pneumonia.

Patient was given antibiotics (ceftriaxone and augmentin) and antiepileptic (sodium valproate) drugs along with lthyroxine. Hemodialysis could not be undertaken because of persistent hypotension. He remained comatose for the next three days but no seizure occurred after that. On Day 3 he succumbed to his illness.

Neurological side-effects of lithium can be mild, in the form of tremor, headache ${ }^{[1]}$ and fatigue only or they can be severe, in the form of muscle fasciculations, weakness, ataxia, slurred speech and extrapyramidal syndrome. Both our patients had tremor from onset, however, extrapyramidal rigidity was only present in Case 1. Lithium decreases seizure threshold leading to isolated 


\begin{tabular}{lll}
\hline \multicolumn{2}{c}{ Table 1: Laboratory investigations of Case $\mathbf{1}$ and $\mathbf{2}$ at time of } \\
& admission \\
\hline Lab Investigations & Case $\mathbf{1}$ & Case $\mathbf{2}$ \\
$\mathrm{Hb}(\mathrm{g} / \mathrm{dl})$ & 11.5 & 9.3 \\
White cell count(cumm) & 27,000 & 7800 \\
Urea(mg/dl) & 121 & 72 \\
creatnine $(\mathrm{mg} / \mathrm{dl})$ & 1.91 & 1.46 \\
Serum lithium $(\mathrm{mmol} / \mathrm{L})$ & 4.86 & 2.8 \\
CBZ level(mg/L) & 10.8 & - \\
Serum calcium(mg/dl) & $6.83 \mathrm{mg} / \mathrm{dl}$ & 7.9 \\
EEG & Generalized & Generalized \\
& slowing & slowing \\
MRI brain & normal & normal \\
CSF & normal & normal \\
\hline
\end{tabular}

seizure (Case 1) or it may lead to status epilepticus (Case 2). Our Case 2 had status epilepticus leading to aspiration pneumonitis, hypotension and death. Acute toxicity may also cause impairment of consciousness, coma and death. Both our cases had unconsciousness and unfortunately Case 2 died. Delayed side-effects may include ataxia ${ }^{[2]}$, cerebellar signs and syndrome of irreversible lithium-effectuated neurotoxicity (SILENT). ${ }^{[3]}$ Permanent neurological deficits due to lithium toxicity may also cause deficits in recent memory $\operatorname{loss}^{[4]}$ and rarely Creutzfeldt-Jakob-like syndrome. ${ }^{[5]}$

\author{
S. Pandey, S. Jain, R. Chatterjee ${ }^{1}$ \\ Departments of Neurology and ${ }^{1}$ Psychiatry, Bhopal Memorial \\ Hospital and Research Centre, Bhopal, India. \\ Corresponding author: \\ Dr. Sanjay Pandey, Flat 91, Prashant Apartment, Plot no 41, \\ Patparganj, Delhi-110 092, India. \\ E-mail: sanjaysgpgi2002@yahoo.co.in
}

\title{
References
}

1. Bigal ME, Bordini CA, Speciali JG. Daily headache as a manifestation of lithium intoxication. Neurology 2001;57:1733-4

2. Megna J, O'dell M. Ataxia from lithium toxicity successfully treated with high-dose buspirone: A single-case experimental design. Arch Phys Med Rehabil 2001;82:1145-8.

3. Adityanjee, Munshi KR, Thampy A. The syndrome of irreversible lithiumeffectuated neurotoxicity. Clin Neuropharmacol 2005;28:38-49.

4. Apte SN, Langston JW. Permanent neurological deficits due to lithium toxicity. Ann Neurol 1983;13:453-5.

5. Goto F, Kano S, Ogawa K. Creutzfelt-Jakob disease presenting hyperparathyroidism. Auris Nasus Larynx 2000;27:281-3. 